\title{
Alternatives to Radiation Investigations in Orthodontics
}

\author{
Shazia Naser-Ud-Din \\ School of Dentistry, University of Queensland, Brisbane, \\ Australia
}

\section{Introduction}

There has been a massive paradigm shift in investigatory tools at present. A greater surge of interest in soft tissue analysis, real time imaging and functional recordings to enhance our understanding of the complexity of the biological system is underway; with high emphasis on non-invasiveness and cost effectiveness. Current studies are looking at the possibilities of using non-ionizing alternatives to derive the required parameters to diagnose, treatment plan and evaluate the orthodontic case. This is in stark contrast to some decades ago where static hard tissue investigations were considered gold standard.

This chapter will explore the different investigations traditionally used for Orthodontic treatment planning and evaluation of treatment objectives. Since the introduction of lateral cephalometrics in 1931 by Broadbent and Hoffrath this 2 dimensional investigation has been considered the ultimate. However, it has several key limitations - radiation exposure particularly for growing children, 2 dimensional representation of a 3 dimensional living body with static image output. The need to provide a more holistic view to the case assessment with new investigatory tools like 3D imaging, ultrasonography, video recordings and EMG are perhaps the way for the future to assess growing living functioning body.

At the time of writing there is a wide array of imaging technology with innovative developments occurring at a phenomenal pace. Nearly every time one searches the world wide web something new is presented. The new hype- 3D video softwares are considered to be the next big thing ${ }^{1}$. The imaging industry finds wide application in defence, architecture, resource industries and general entertainment. In the medical field, it has immense application for diagnosis and potential to generate understanding not previously possible with 2D investigations. The classic examples are MRI and CT scans ${ }^{2-6}$.

In orthodontics, the focus is more based on the external features and soft tissues and 3D reproductions are invaluable not only for diagnosis in general medical scenarios, but more so for treatment evaluation and long-term growth changes. However, the majority of published work tends to come from Japan followed by European and USA researchers ${ }^{7-9}$.

In this chapter a brief historical background of the different imaging techniques namely Lateral cephalometrics, sEMG, Ultrasonography \& 3D imaging as used in contemporary investigations along with important findings from recent studies from author's research involving such technology are discussed. 


\section{Lateral cephalometrics}

Lateral cephalometric techniques have dominated in mainstream orthodontic, orthognathic and dentofacial growth studies for over seven decades. It is considered a versatile tool and has served the profession well since it was first introduced in 1931 by Broadbent 10 . Cephalograms have improved our understanding of growth through seminal research 11,12. It is an important diagnostic tool utilized extensively in orthodontics. Recent literature search brought out 28,200 items related to "lateral cephalometrics in Orthodontics" while a similar search on PubMed found 808 documents on related topics. This highlights the volume of work done in the field.

There are two major limitations with cephalometrics; primarily, the additive radiation dosage of progressive films and, secondly, it is a two dimensional representation of the three dimensional craniofacial region. Moreover, the validity of cephalometric analyses has been questioned ${ }^{13}$ and there have been concerns about the application of such simple analyses in diagnosis and treatment planning. Errors generally are attributed to orientation, geometry and association. A meta-analysis was conducted on six studies for random and systematic error along with repeatability and reproducibility ${ }^{14}$ with good repeatability found for limited landmarks namely menton (Me) posterior nasal spine (PNS) anterior nasal spine (ANS) sella (S) pterygomaxillary fissure(Ptm) point A deepest point on the anterior maxillary margin (A) and point $\mathrm{B}$ deepest point on the anterior symphysis region of the mandible(B).

A number of computer software sites such as the Dolphin ${ }^{\circledR}$ (Los Angeles CA, USA), Mona Lisa ${ }^{\circledR}$ (Tidbinbilla, Canberra, Australia) (Fig.2) etc. are available to analyse the lateral cephalogram with multiple analyses at a click or a mouse scroll. However, the computer analyses have also been criticized for error through loss of contrast, related to pixel size and poor calibration. Overall, the trained eye can effectively trace and resolve finer details up to $0.1 \mathrm{~mm}$ or smaller 15 as compared to $2.48 \mathrm{~mm}$ accuracy recorded from Active Appearance Models (AAM) which is a computer program designed to locate landmarks ${ }^{16}$. Such technology needs refinement with mathematical model in order to provide a higher level of accuracy and reproducibility with work in progress by most of the softwares.

Furthermore, the lateral cephalogram has been supplemented with other radiographic conventional images such as panoramic radiography, periapicals, and hand wrist films. The later is now being replaced by the cervical maturation index (CMI) which can be derived from standard lateral cephalograms reinforcing the trend towards minimizing radiation exposure in growing individuals.

There is a galaxy of analyses to choose from. One needs to be mindful of the analyses being a composite of several unique dimensions often with a signature eponym. So it is imperative to choose specific dimensions of relevance to the study at hand. Prudent selection of analysis proves to be time efficient. Figure 1 depicts the basic linear, angular and proportional analysis for majority of diagnostic features commonly required for treatment planning in Orthodontics.

The common range and standard deviations for the different variables from a recent study are given in Table 1. These reflect the general spread for the variables elicited in Fig.1( part of the research project of Dr S Naser-ud-Din for the fulfillment of PhD University of Adelaide 2009) ${ }^{18}$. 


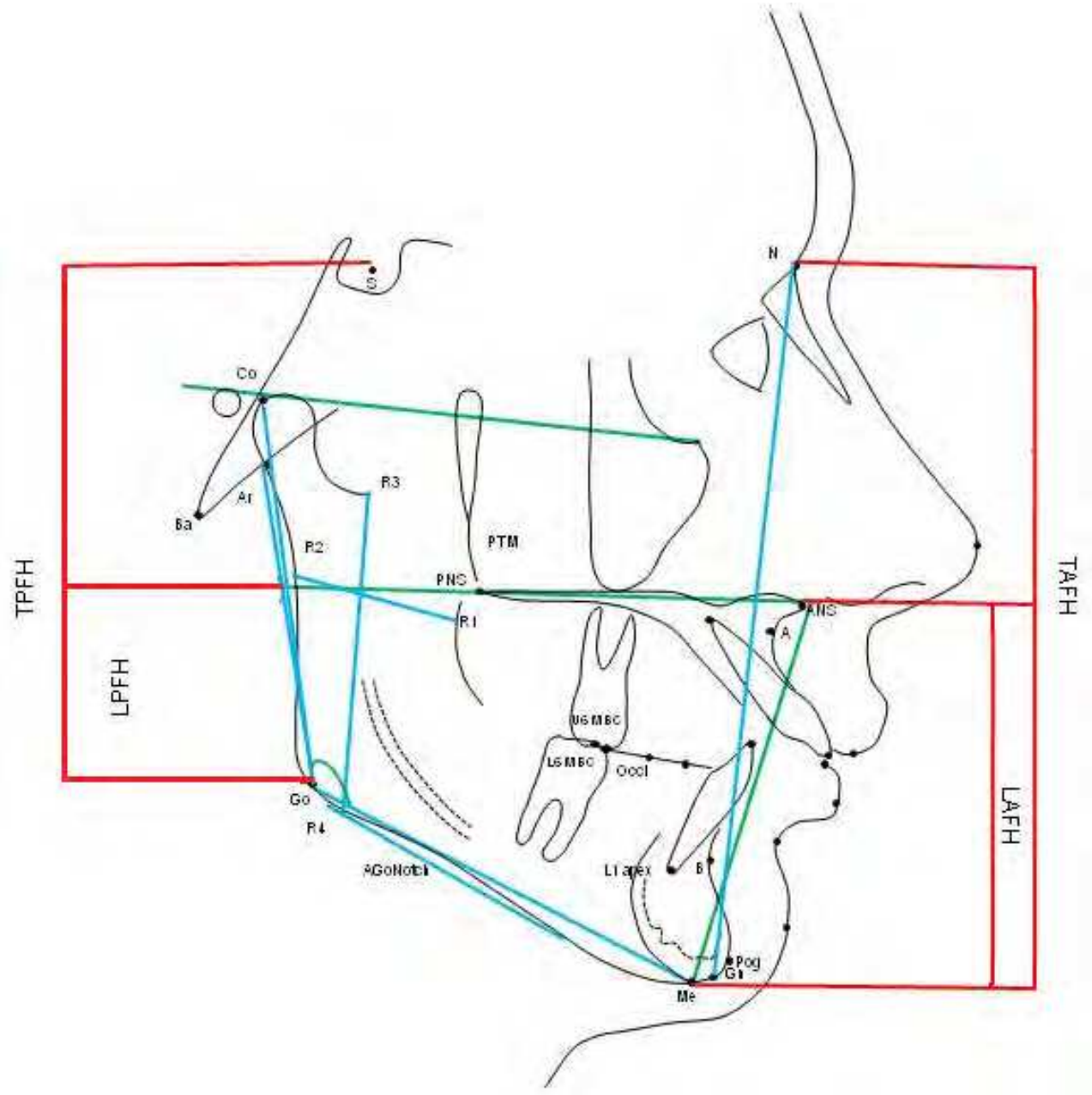

Fig. 1. Lateral Cephaolmetric with Linear (Blue)- 9 linear ( Co-Go, Ar-Go, Go-Me, Masseter Length, R1-R2, R3-R4, N-Me, N-Gn, AGoNotch).Angular (Green) -6 angular (GoAngle, UGoAngle, LGoAngle, Max-Man, Frankfort Horizontal to Mandibular plane, ODI) \& Proportional (Red) analysis-5 proportional (NGn-ArGo, LAFH/TAFH,LPFH/TPFH, ArGoGoMe, Jarabak Ratio) ${ }^{17}$ 


\begin{tabular}{|c|c|c|c|c|c|}
\hline & Variables & Abbreviations & Mean & $\mathrm{SD}$ & Range \\
\hline 1 & Condylion-Gonion & Co-Go & $64.3 \mathrm{~mm}$ & $(6.0)$ & $55.4-79.7$ \\
\hline 2 & Ante-Gonial Notch & Ago-Notch & $1.9 \mathrm{~mm}$ & $(0.6)$ & $0.9-3.2$ \\
\hline 3 & Articulare-Gonion & Ar-Go & $45.8 \mathrm{~mm}$ & $(5.2)$ & $35.3-55.4$ \\
\hline 4 & Gonion-Menton & Go-Me & $73.7 \mathrm{~mm}$ & $(4.6)$ & $65.4-80.8$ \\
\hline$>$ & Nasion-Gnathion & N-Gn & $107.7 \mathrm{~mm}$ & $(6.8)$ & $96.9-121.3$ \\
\hline 6 & Ricketts R1-R2 & R1-R2 & $29.2 \mathrm{~mm}$ & $(3.9)$ & $21.7-36.2$ \\
\hline 7 & Ricketts R3-R4 & R3-R4 & $48.0 \mathrm{~mm}$ & $(6.5)$ & $39.6-58.0$ \\
\hline 8 & Masseter Length & ML & $56.3 \mathrm{~mm}$ & $(5.6)$ & $44.6-65.8$ \\
\hline 9 & Nasion-Menton & $\mathrm{N}-\mathrm{Me}$ & $110.4 \mathrm{~mm}$ & $(7.4)$ & $99.2-126.6$ \\
\hline 1 & $\begin{array}{l}\text { Maxillary - } \\
\text { Mandibular Plane }\end{array}$ & Max-Man & $21.3^{\circ}$ & $(6.2)$ & $10.2-36.5$ \\
\hline$\frac{\ddot{d}}{\frac{\pi}{\sigma}}$ & $\begin{array}{l}\text { Frankfort Horizontal } \\
\text {-Mandibular Plane }\end{array}$ & FH-Man & $21.8^{\circ}$ & $(6.3)$ & $13.2-36.1$ \\
\hline 3 & Upper Gonial Angle & Go Angle U & $49.9^{\circ}$ & $(5.5)$ & $41.6-63.6$ \\
\hline$\frac{\pi}{2}$ & Lower Gonial Angle & Go Angle L & $68.3^{\circ}$ & $(5.2)$ & $60.1-82.1$ \\
\hline 5 & Gonial Angle & Go Angle & $118.2^{\circ}$ & $(7.8)$ & $102.7-134.6$ \\
\hline 6 & $\begin{array}{l}\text { Overbite Depth } \\
\text { Indicator }\end{array}$ & ODI & $73^{\circ}$ & $(7.8)$ & $56.5-92.3$ \\
\hline 1 & $\begin{array}{l}\text { Nasion-Gnathion/ } \\
\text { Articulare Gonion }\end{array}$ & NGn/ArGo & 2.2 & $(0.2)$ & $1.8-2.7$ \\
\hline$\frac{\stackrel{0}{d}}{. \frac{\pi}{2}}$ & $\begin{array}{l}\text { Articulare Gonion / } \\
\text { Gonion Menton }\end{array}$ & ArGo/GoMe & 0.7 & $(0.1)$ & $0.6-0.9$ \\
\hline శ్ & $\begin{array}{l}\text { Lower Anterior Face } \\
\text { Height }\end{array}$ & LAFH/TAFH & $57.1 \%$ & $(3.9)$ & $47.1-63.3$ \\
\hline مे & $\begin{array}{l}\text { Lower Posterior } \\
\text { Face Height }\end{array}$ & LPFH/TPFH & $73.4 \%$ & $(6.4)$ & $59.1-84.2$ \\
\hline 5 & Jarabak Ratio & J Ratio & $83.6 \%$ & $(6.5)$ & $71.0-95.7$ \\
\hline
\end{tabular}

Table 1. Common distribution for the variables from cephalometrics. ( Part of the doctorate project Dr S Naser-ud-Din University of Adelaide Australia, 2009) 


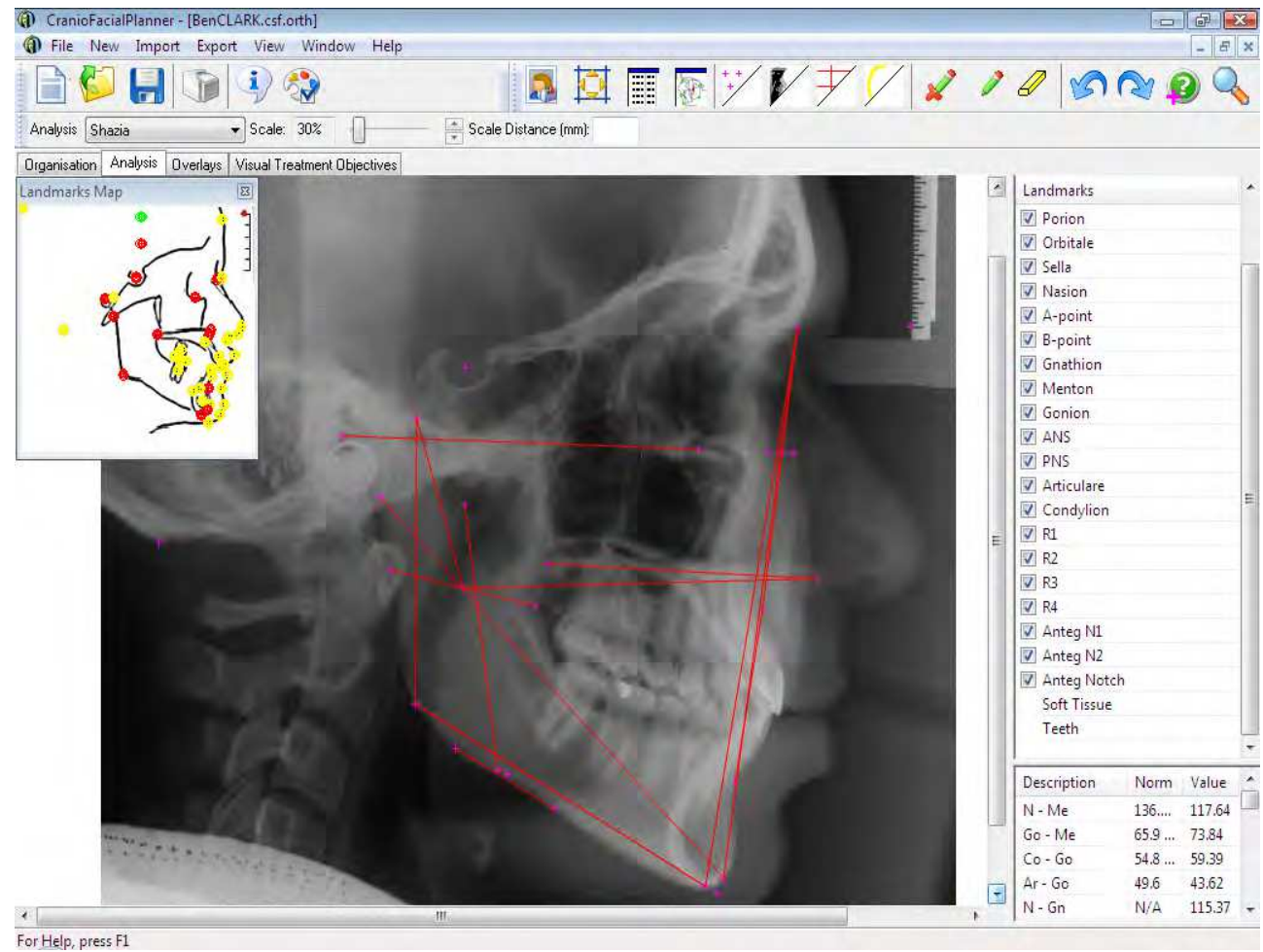

Fig. 2. MonaLisa ${ }^{\circledR}$ Program for custom made cephalometric analysis. For efficient and standardized analysis computer based software packages are widely utilized.

\section{3. sEMG (surface Electro Myo Graphy)}

Our understanding of the neurophysiology of the muscles of mastication has increased substantially in the past 60 years. With the introduction of electrophysiological tools in the 1950 's 19, an array of experimental protocols have become available around the globe. Although, the majority of studies have used animal models due to the invasiveness of the procedures, results from such studies still provide valuable data that is extrapolated into humans. The earliest EMG studies reported on muscles of mastication during basic mandibular movements were from Carlsöö(1952), Göpfert \& Göpfert (1955) in Moller( Moller $1966^{20}$. These preliminary studies improved our fundamental understanding of the complex masticatory system. Other work of historical interest is from Perry \& Ahlgren ${ }^{21,22}$.

EMG registers signals of muscle contractility through action potentials delivered by the motoneurones. Highly refined bipolar surface electrodes are sensitive to these electrical signals and, once amplified, are visible as the EMG recordings.

In the human model, indirect methods are employed and are preferably, non-invasive. Surface electromyography (sEMG) is a tool that is used extensively to explore the neural circuitry. Although, it has its limitations (discussed later) is overall considered user-friendly, non-invasive and has extensive applications in neurophysiology. 


\subsection{Development of sEMG devices}

The first chewing apparatus was described by Moller in $1966{ }^{20}$. It was a landmark achievement in which bipolar recordings could be saved on photographic oscilloscopes rather than printed by inkwriters. Therefore, several experiments were designed to enhance our understanding of muscle activity during chewing, postural activities, full effort clenching, swallowing patterns and even facial morphology. This innovative apparatus only required an EMG recorder with electrodes. The electrical activity was recorded on three channels. Although, an advanced methodology for its time, Moller's apparatus had the serious limitation of un-standardized positioning of the subject. This produced a lack of reproducibility, albeit the reproducibility factor poses a challenge even with contemporary advancements. Other methodological issues arose from interference from neighbouring potentials, rejection of common voltage, distortion of amplitude and uneven distribution of electrical activity ${ }^{20}$. Over time, several global studies have been conducted which have improved designs and chewing devices 23,24 leading to an enhanced understanding of the reflexes in the oro-facial regions.

The periodontal-masseteric reflex was first described by Goldberg 197125 highlighting the importance of not only PMR but also the role of the masseter muscle and central connections, due to the short latency. This study concluded that there was a central connection located in the mesencephalic nucleus that was responsible for the excitatory masseteric reflex evoked by PMR and gingival receptors. One can appreciate that, even with a very simplistic methodology and manual tapping of the teeth, Goldberg was able to deduce these important findings.

\subsection{EMG studies and significance in orthodontics}

Work in this field has resulted in few conclusive findings. A canonical correlation analysis between facial morphology, age, gender and EMG during rest and contraction has not found a statistically significant correlation 26. EMG and bite force have been studied extensively 20,27,28 with consistent findings of reduced force levels in dolichofacial patterns.

Different vertical facial types, both in adults and children, produce differences in EMG responses recorded over the course of a day ${ }^{29}$. Masseter muscle EMG activity was found to be consistently longer in short vertical dimension facial types as compared to high mandibular plane angle individuals. The variables of bite force, muscle efficiency and mechanical advantage in children with vertical growth patterns 30 were negatively correlated with muscle efficiency and vertical proportions.

Morimitsu et al. documented recordings of EMG from masseter muscles which showed positive correlations with linear cephalometric measurements; particularly, the muscle activity was significantly related to mandibular dimensions such as (Co-Go) and body length (Go- Me) 31. In fact, the muscle activity increased with decrease in vertical proportions such as mandibular plane angle. Furthermore, they compared the muscle activities with anterior-posterior skeletal base relationships indicated by Sella Nasion Point A (SNA) and Sella Nasion Point B (SNB) variables. Morimitsu et al. strongly advocated the use of EMG for examining masticatory activity, but one could argue that the reproducibility with electrode placement at subsequent visits may prove to be a challenge 32 .

A comprehensive study by Tuxen et al. ${ }^{33}$ compared masseter muscle fibre types along with function from EMG and facial morphology. They concluded that even with intensive analysis of different dimensions, linear regression analyses failed to show any significant association highlighting, once again, the complexity of the craniofacial region. 
Muscle spindle reflexes are stronger in short face height individuals ${ }^{17,34}$ which may explain the phenomenon with bruxism and brachyfacial tendency. Moreover, this information may translate into better designs for splints and Orthodontic appliances.

A recent publication 35 has utilized EMG to analyse masseter muscle differences in individuals who brux in their sleep. The authors believe their system can help diagnose different types of bruxism and is aptly termed the innovative bruxism analysing system. Once again, the literature supports the use of sEMG as a useful mode of investigation.

\subsection{Limitations \& methodological issues}

EMG has provided insight into the neuromuscular system but there are inherent limitations which must be minimized in order to derive meaningful data. This has been reviewed thoroughly 36. EMG accuracy may be enhanced by the use of intramuscular electrodes compared with sEMG electrodes. However, sEMG electrodes with built-in amplifiers can assist in reducing cross-talk and movement artifact. Passive surface electrodes require skin preparation and monitoring of resistance below $10 \Omega$ for clear data recording. Contemporary sEMG involves the use of bipolar electrodes, which suppress noise. The amplification should counter distortion, preferably $10 \times$ higher than the electrode-to-skin electrical resistance. The filter level is dependent upon skin thickness and the frequencies recorded. It should not eliminate any of the frequencies within the range of recording and the choice lies between upper (high-cut or low pass) and lower (low-cut or high pass).

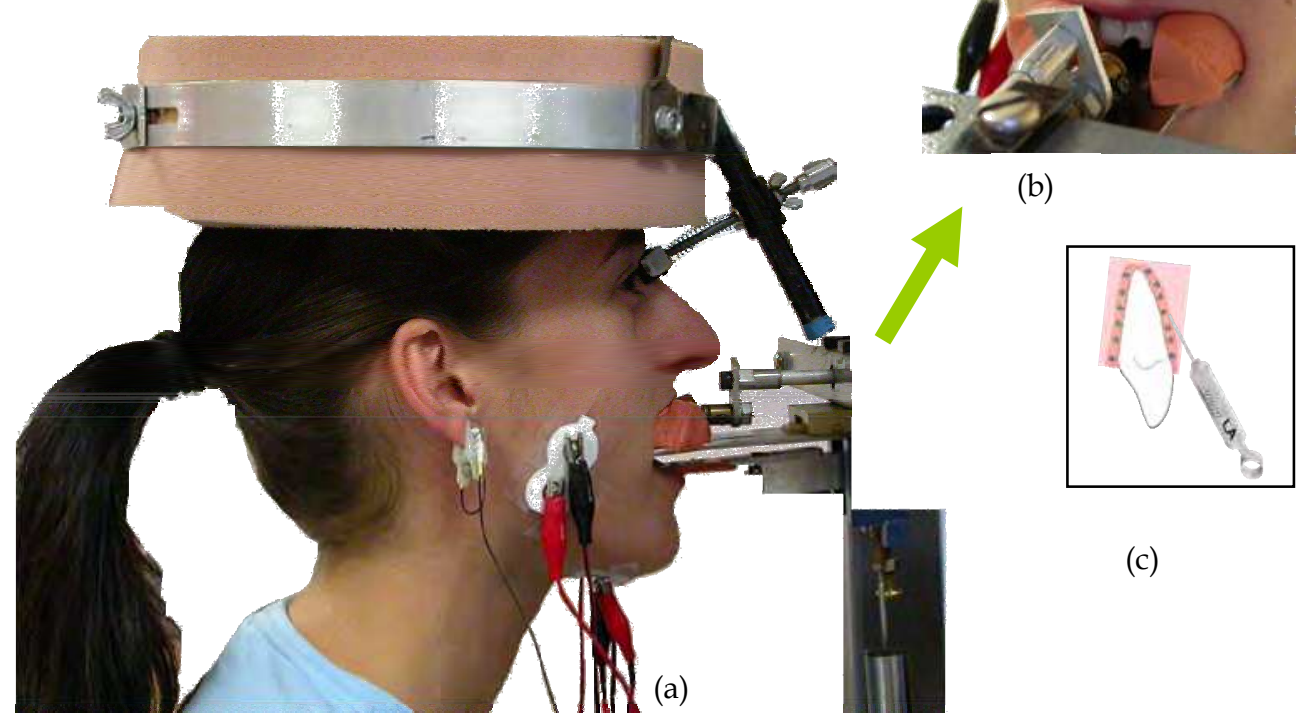

Fig. 3. Subject seated comfortably throughout the experiment session. sEMG recorded bilaterally from the masseter and the digastric muscles: (a) biting on a custom made impression; (b) left central incisor mechanically stimulated by an orthogonal probe;(c) local anaesthetic was infiltrated to eliminate periodontal mechanoreceptor input during the spindle trials. An ear clip provided the electrical ground. 
In addition, the quality of data production is dependent on the recording and display devices, the sophistication of the computer programs to reliably identify the initiation of muscle activity, the type of ground used, and obviating the use of long leads which contribute to noise and, therefore, contamination of the data. Several different types of ground have been utilized in human studies such as forehead, wrist, elbow, ear lobe and lip clips. Currently the ear lobe is selected due to ease of placement and distance from the experiment site (Fig 3).

Minimizing artifacts is essential for clear data recording and minimizing movements from adjacent muscles is very helpful. In the study by author ${ }^{34}$, the customized nose rest and the head halo provided stabilization during the chewing and static phases of the experiments (Fig. 3).

Cross-talk is a phenomenon commonly experienced in sEMG recordings where adjacent muscle activity leads to electrical volume added to the data. Cross-talk can be minimized by standardizing the experimental conditions. Moreover, double deferential techniques can also assist in eliminating cross-talk ${ }^{37-43}$. This is the prime cause of criticism in telemetry sEMG recording where cross-talk and noise can compromise the results ${ }^{44}$.

Finally, correct processing of the data is essential and custom-made software programs are routinely used. IZZY ${ }^{\circledR} 45$, in Fig. 4 provides an array of systematic offline analysis which allows the data from sEMG to be full wave rectified and further processed as CUSUM (Cumulative Sum).

Normalization (Fig.5) is a standardization process for data acquisition which allows comparison between different subjects and with the same subject data on different occasions. It means normalizing sEMG levels to the percentage of an individual subject's MVC (maximum voluntary contraction) for each muscle group, hence reducing the variability between records.

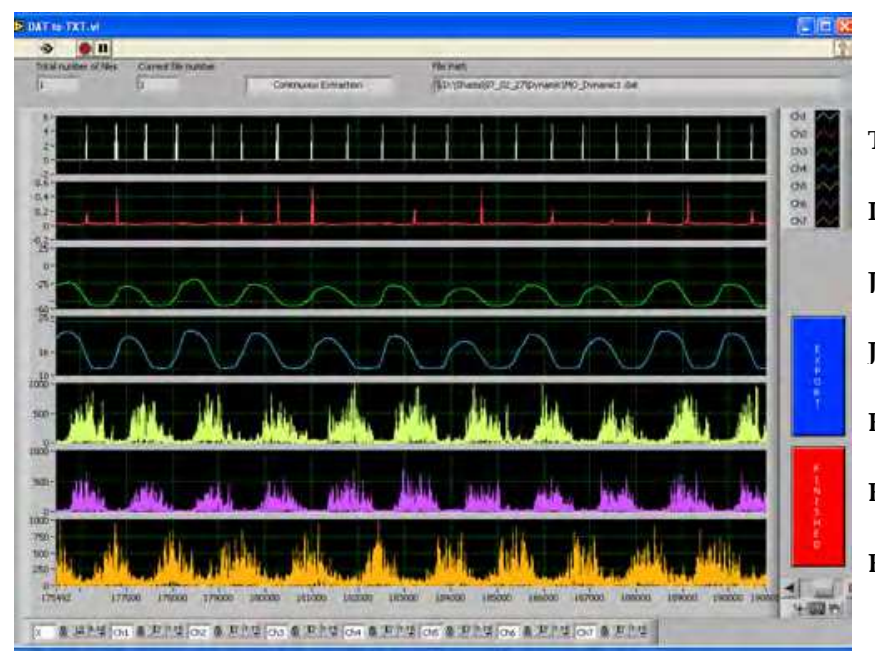

TRIGGERS

INCISAL STIMULUS

JAW FORCE

JAW POSITION

EMG LEFT MASSETER

EMG RIGHT MASSETER

EMG DIGASTRIC

Fig. 4. Recording sEMG screen shot of the computer generated triggers (white), profile of stimulus (red), Jaw force (green), Jaw position in opening and closing (blue) and raw sEMG recorded from left masseter (yellow), right masseter (pink) and anterior digastric (orange). Total of seven channels were operating at the time of the experiments. 


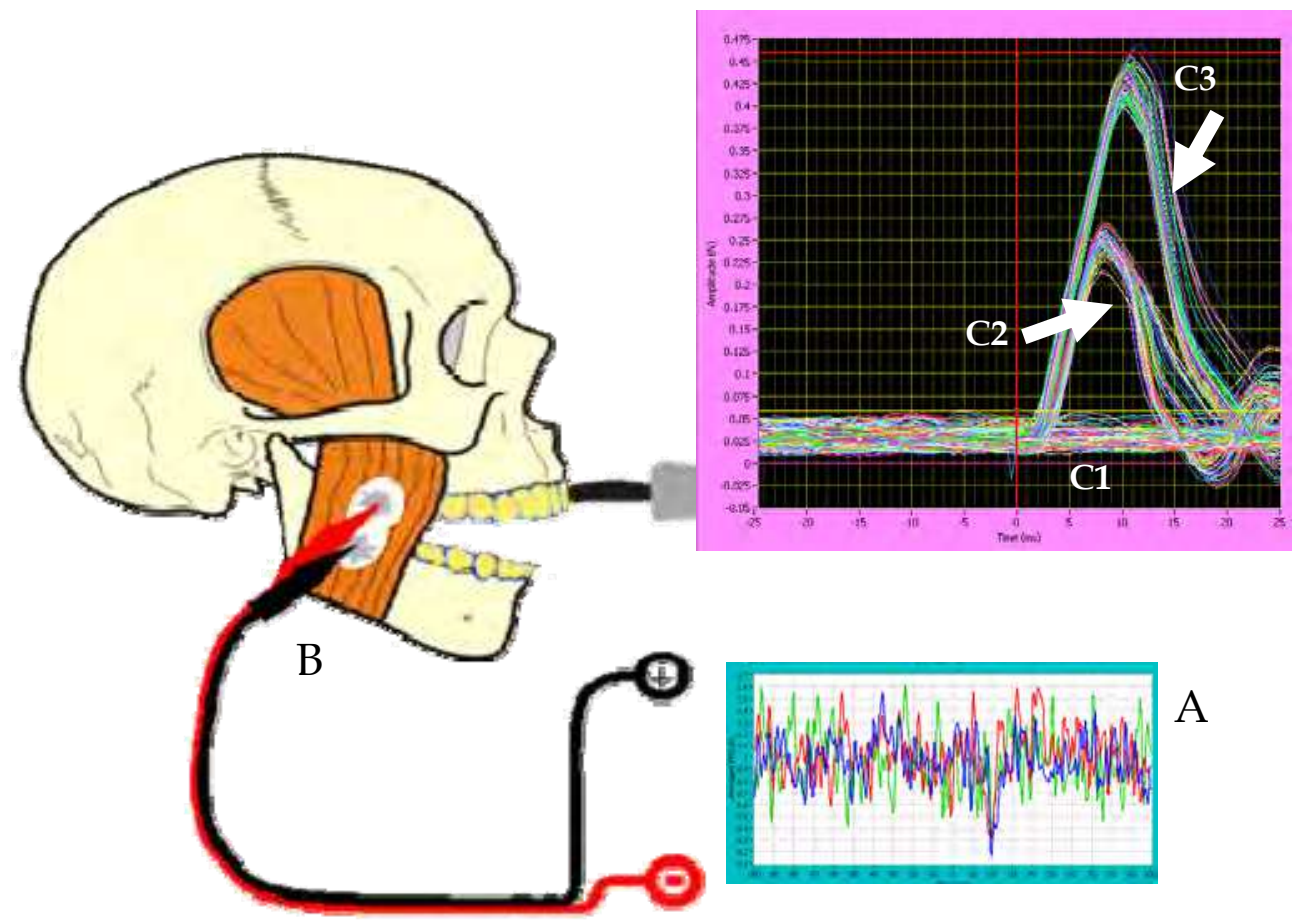

Fig. 5. sEMG (A) was recorded from the masseter (B) during experimental conditions with normalization of the raw scan in A to C1, C2 and C3 (control, with low tap and high force tap to the central incisors).

\section{US (Ultra Sonography)}

Ultrasonography is developing rapidly as the mainstream investigatory tool.

Ultrasonography (US), as the name implies, utilizes sound waves within the frequency of 2$18 \mathrm{MHz}$ that bounce off the tissue to provide the depth and density of the image conventionally captured on the screen as a real time image. It was developed for medical use in the 1940's with parallel developments across the Atlantic in the USA and Sweden. It has since been widely accepted as the safest investigating tool and is applied widely in obstetrics. However, it has applications across several medical disciplines including physiotherapy therapeutic outcomes for muscular-skeletal conditions. It is now easily available infact handheld devices which are easy to use and with higher resolution are making way into the clinical set ups and for field work. The 3D graphics along with real time color coding will indeed provide greater understanding and acceptance in the future to evaluate functioning muscles. There has been a major paradigm shift with realization that form and function are inextricably intertwined in Orthodontics. Our understanding of the hard tissue relationship has been comprehensive, with extensive clinical trials both cross sectional and longitudinal over the past several decades. The majority of studies have used 
standardized cephalograms that reflect our current concepts. However, the same cannot be stated for soft tissues and, more specifically, the muscles that envelope the skeletal bases. Hence, the interest with non-invasive soft tissue real time evaluation with US.

The hypothesis was that if such a simple non-invasive investigation can provide diagnostic data then it would obviate the need for radiation investigations, in particular for randomized controlled clinical trials (RCCT) that are currently considered the highest caliber of evidence based literature. Such study designs require several radiographs which are difficult to justify ethically. Hence, non-invasive US could prove vital for long term studies.

US is advancing from $2 \mathrm{D}$ to $3 \mathrm{D}$ imaging whereby a series of $2 \mathrm{D}$ images are collated and rendered into $3 \mathrm{D}$. The main limitation is cost as it needs a specialized probe and the image acquisition speed is relatively slow, especially in moving tissues such as contracting muscles. Further advances with colour Doppler technology are of value for imaging tortuous vessels. Generally speaking, conventional US serves well and is good for imaging muscles and soft tissues, but has poor acoustic impedance for bone.

Muscles of mastication have been studied extensively with US which has been considered to be a valuable, precise technique for analysing muscle shapes ${ }^{46-49}$.

Furthermore, US is superior to radiographs for soft tissue evaluation and definitely overcomes the radiation hazards. The surface topography for the masseter muscle is excellent due to its superficial anatomical position Fig. $6 \& 7$ ); however, the volume and cross-section assessments have been difficult 50 . Hence, the present study sought to evaluate these dimensions with a simplified approach and using arithmetical formulas ${ }^{51}$.

A comprehensive meta analysis was recently presented by Serra in 200850 which reported masseter muscle thickness in contraction to range from $5-14.1 \mathrm{~mm} 52,53$. One could argue that this wide variation would be due to racial or ethnic diversity not to mention the time of recording be the muscle relaxed or tensed in contraction. US has recorded thickness variations in masseter muscle contraction and relaxation 49 during function which would otherwise have been impossible with snap exposure type investigations.

US has been extended to determine association between several variables such as the masticatory muscle thickness, TMD and bite forces ${ }^{54}$. The study found a positive correlation between masseter muscle thickness and posterior facial dimensions. The study concluded that muscle thickness is related to vertical facial dimensions and bite force. Previous studies have had similar findings in large samples where not only negative relations between muscle thickness and anterior facial heights and mandibular lengths were noted but positive relationships existed with intergonial width and bizygomatic facial width according to anthropometric measurements 55,56 . Likewise, a Swedish study consistently found a relationship between thin masseter and longer faces in females ${ }^{57}$. This study found US to be a reliable and accurate method for muscle assessment.

Hatch and associates have clearly indicated the importance of multivariate analyses of the masticatory system for comprehensive diagnosis in dentistry ${ }^{58}$. They went so far as to include blood glucose levels along with bite force and cross-sectional area of the masseter muscle.

Overall, US has been documented as a reproducible and reliable investigating tool for masseter muscle assessment 59,60 and could produce useful, non-radiological information to enhance orthodontic practice. 


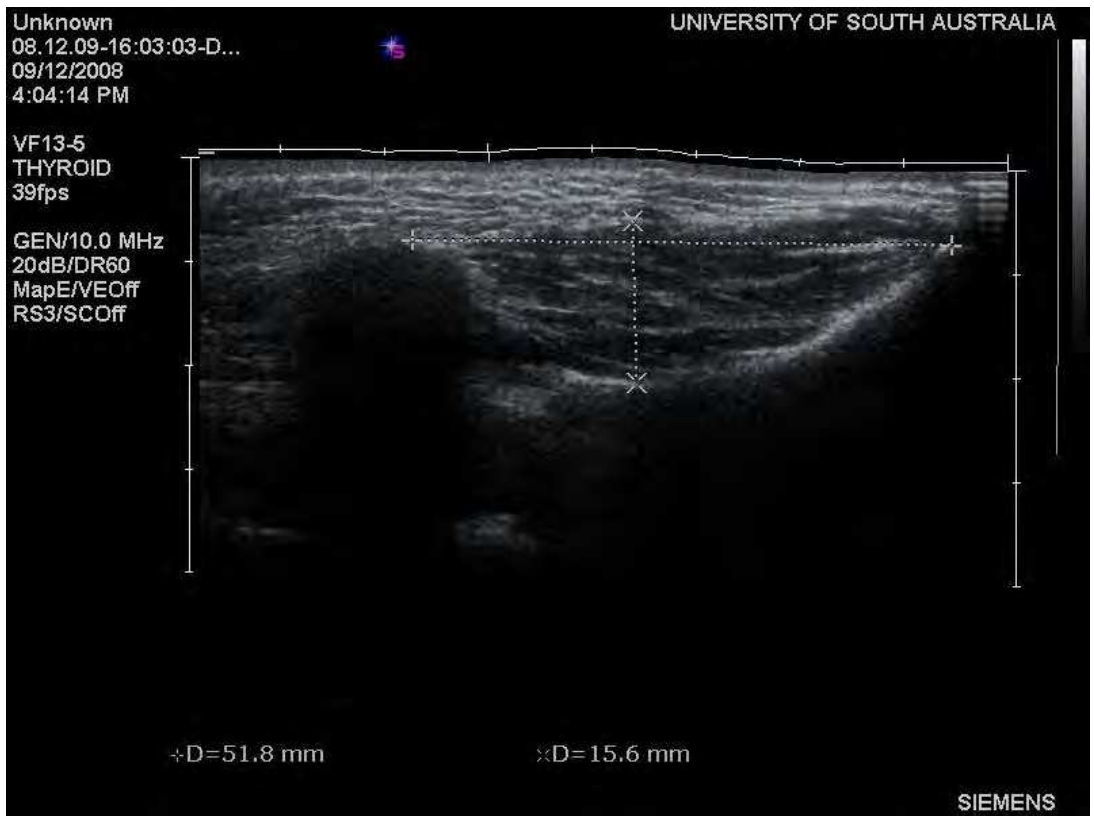

Fig. 6. US Scan of the left masseter showing (dotted lines) the length (horizontal line) and the thickness (vertical line)

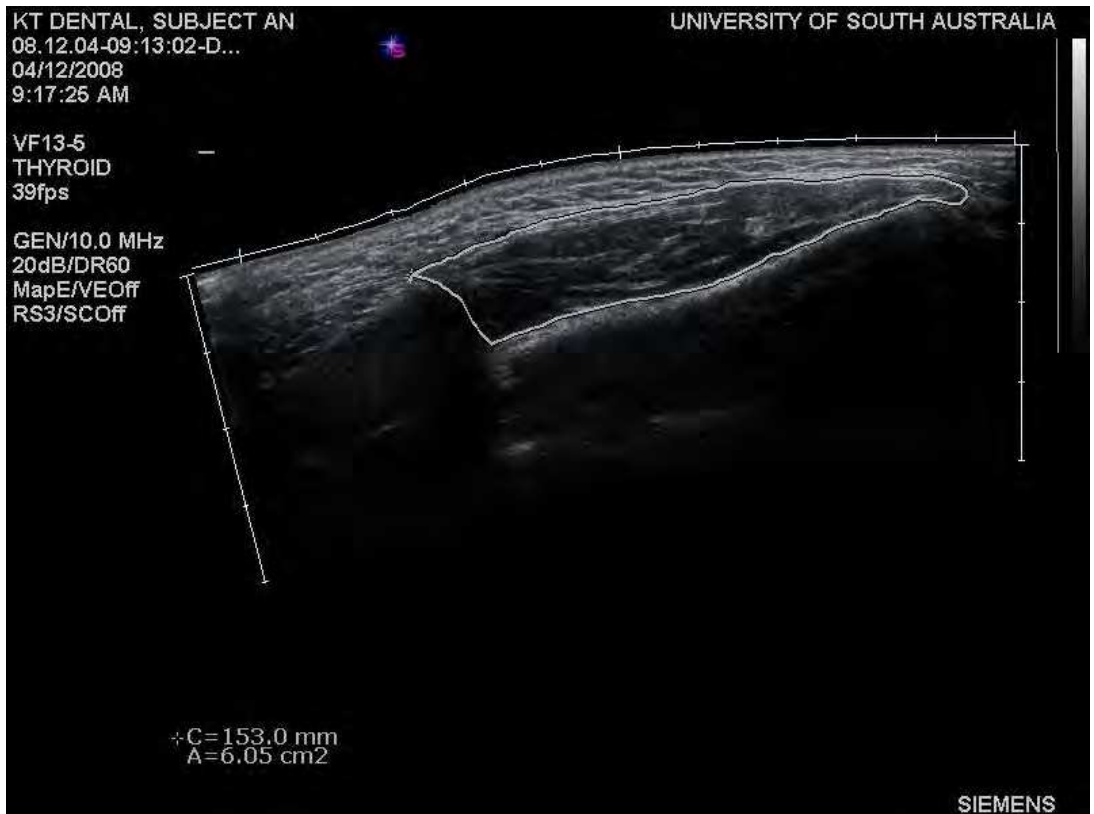

Fig. 7. Area measured manually by tracing the circumference of the masseter muscle (B). 


\section{3D imaging}

3D imaging has come a long way in the last 20 years, particularly since its introduction six decades ago [Thalmann-Degen 1944] ${ }^{61}$. Primarily developed for application in industry 62 as an effective and non-invasive method, it quickly found its way into clinical applications, particularly in orthodontics ${ }^{63}$ and oral surgery. 3D applications in restorative dentistry with the Cerec technique and CAD-CAM are already in main stream clinical application and boast high accuracy at the level of 70 microns 64 . Scanning of comparably smaller dimensions of hard surfaces with accurate reproduction has evolved over the past few years 7 . A similar level of precision is desired for facial soft tissue imaging. It's only a matter of time and refinement of technology until 3D imaging becomes a routine part of private orthodontic practice ${ }^{65}$. With innovative robotic wire bending, tailormade appliances both labial and lingual (Insignia, SureSmile 66 and Incognito-3M Unitek USA ) 3 D imaging is gaining an integral component of how Orthodontics shall be delivered in $21^{\text {st }}$ century.

In orthodontics, 3D imaging was tested for the first time in 1981 with optical surface scans $67-$ 69. A major change came with the use of a hand-held scanner making the scan portable (McCallum et al.; 1996 in Moss $^{70}$ ) followed by a probe to record 3D coordinates ${ }^{55}$. Imaging is sensitive to the surface acquisition and sufficient data are required to appreciate the subtle changes that occur in soft tissues over a period of time.

There are various types of imaging techniques ranging from stereo photogrammetry, to 3D laser scanning, vision-based scans like Moiré tomography along with the latest, safest and most cost- effective structured light 3D imaging ${ }^{9}$. Innovative approaches are under way to integrate the conventional lateral cephalogram with stereo photogrammetry and digital fusion. It is claimed that such techniques will obliterate errors through image sensors and 3D orientation 71 .

Structured light creates a superficial shell-like reproduction of the face enabling the digitized topology of the face to be displayed in $3 \mathrm{D}$ without any ionizing radiation ${ }^{71}$. It is a simple and cost effective method of generating three-dimensional images with minimal time required for exposure, usually within one second.

The structured light (SL) technique provides reasonable accuracy when following certain protocols such as the exposure should be frontal with deviations of up to $+/-15^{\circ}$ only because with increasing profile view there is proportionally reduced accuracy. Linear measurements can be erroneous up to $1 \mathrm{~mm}$ and if that is acceptable to the operator and duly accounted for it should not be of much concern. Likewise, the smaller inter-distance between the two cameras creates a limited field of view leading to diminished accuracy in zcoordinate measurements 72 .

Overall, SL is considered a simple, cost effective and readily applied 3D imaging system ${ }^{73}$. It is based on stereoimaging and triangulation to produce a 3D image. From a light grid or pattern which is usually horizontal Fig.8. The mean absolute error for linear measurements with SL 3D imaging in the current study was $0.53 \mathrm{~mm} 18,74,75$.

$3 \mathrm{D}$ imaging is valuable in assessing the growth changes in soft tissues over time, because previous investigating methods were not able to adequately assess soft tissue changes related to growth. A large scale growth study with 3D optical surface scanning ${ }^{76}$ found significant changes in the vertical facial dimension with increase in the cross sectional cohort age range 5-10 years old. Moreover, they found a significant increase in dimension in the masseter muscle mass across the age range. Hence, age-related changes can be appreciated and quantified with 3D imaging. Furthermore, a longitudinal study analysing facial 
morphology changes also found similar results with an increase in the vertical dimension being gender dependent with greater significance in males ${ }^{8}$.

Similarly, growth changes have been evaluated with 3D facial morphometry and Fourier analyses depicting changes in profile ${ }^{77}$. Another area where 3D imaging is used extensively concerns pre- and post-orthodontic treatment effects on soft tissues. The very controversial and anecdotal references often made regarding functional orthopaedic appliances has been backed with evidence ${ }^{78-80}$. Yet another highly contentious issue in orthodontics has been the extraction and non-extraction debate, where the treatment decision pendulum keeps swinging by the decade. A study in London ${ }^{81}$ used 3D optical surface scans for patients with fixed appliances; one group with extractions and another without. The results were conclusive and laid the age-long controversy to rest with no significant facial soft tissue changes discernable in either study group.
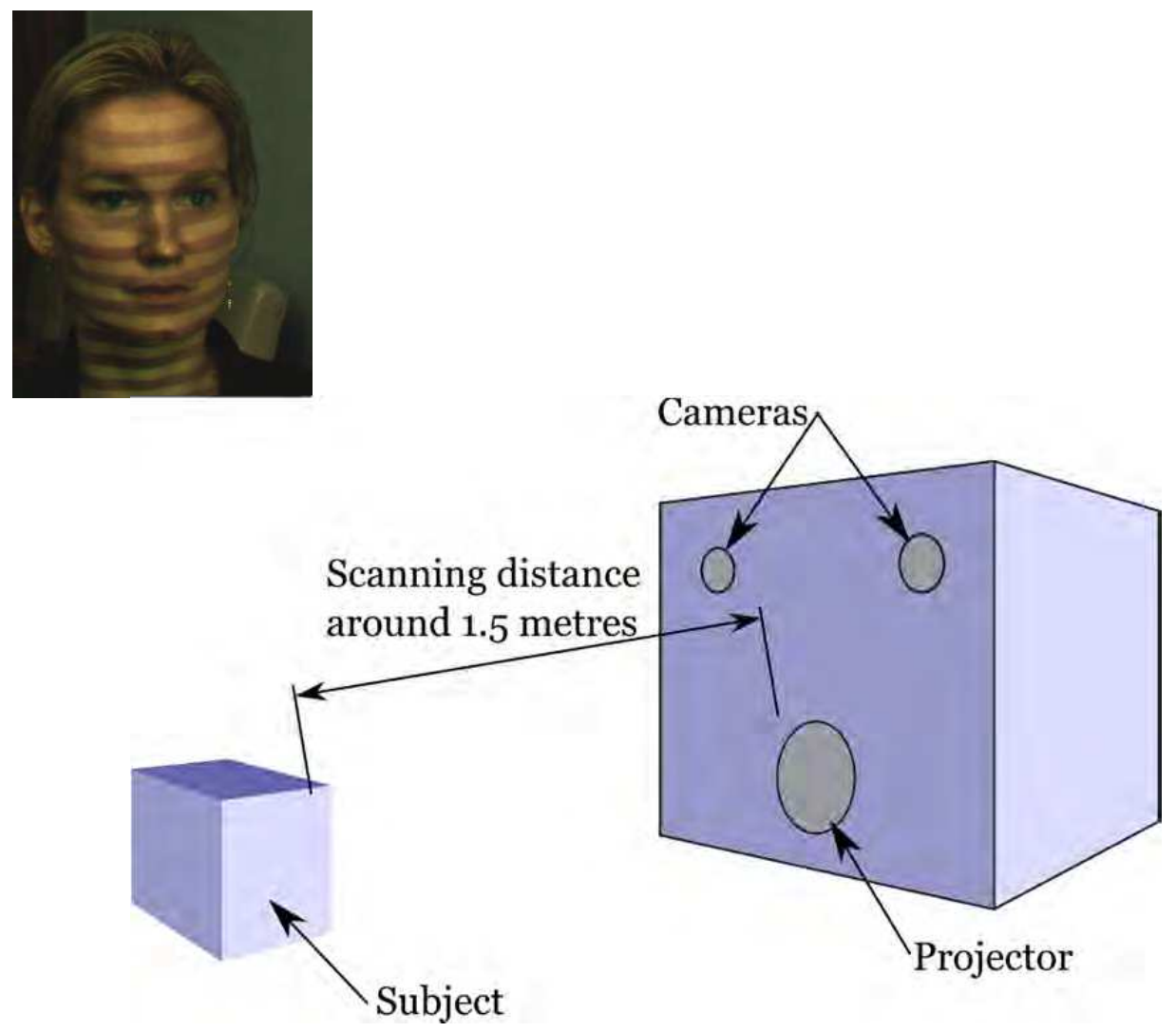

Fig. 8. Capturing an image with the 3D structured light projector placed $1.5 \mathrm{~m}$ from the subject. The grid of light with horizontal pattern is flashed on the subject's face for 1sec. Triangulation helps to generate the 3D effect. 
Work is underway to fabricate user-friendly analysis methods especially as 3D imaging is relatively contemporary and lacking well-established quantification and comparison techniques. 3D studies conducted with Procrustes analysis have determined the translation of soft tissues in monozygotic and dizygotic twins ${ }^{70}$. Another study has used the Procrustes registration method in conjunction with 3D CT scan and Virtual Reality Modelling Language (VRML) to assess the registration error associated with such techniques and found it to be within $+/-1.5 \mathrm{~mm}$ in most parts ${ }^{82}$. A South Korean study 83 found negligible error of $0.37 \mathrm{~mm}$ and less than $0.66 \%$ magnification with laser scanners. They claim that the soft tissue rendering was highly reliable and reproducible. However, one would argue about the safety of such imaging as the study was not conducted on humans but mannequins.

Unique to anthropometry and $3 \mathrm{D}$ imaging is the ability to measure and evaluate the transverse dimensions of the face. Although, a large list of measurements are presented from the frontal aspect in the Farkas textbook 55 for diagnostic purposes one should consider selected ones.

Two horizontal planes commonly used for facial widths are the bizygomatic diameter, interzygonion (zy-zy), and mandibular or lower face width, inter-gonion (go-go). Generally, such evaluations assist in picking up asymmetry greater than $2 \mathrm{~mm}{ }^{84}$. These dimensions form indices for facial proportions. Thus, the Facial Index was calculated with horizontal (zy-zy) as a percentage of vertical from nasion and gnathion (n-gn). Similarly, the (go-go) width is used in the Jaw Index with stomion to gnathion as the lower face proportion (Fig.9).

The midline landmarks were used for vertical proportions which were Index of lower jaw to facial height and Index of Jaw to facial height. These proportions are related to the lateral cephalogram and the correlations can be beneficial substitutes in progressive evaluation over the course of the treatment.

The curvilinear measurements were included because they are more biologically meaningful than straight line representations of complex 3D structures (Fig.10). For example, our findings show a significant difference $(\mathrm{p}<0.0001)$ at $95 \% \mathrm{CI}$ and with a standard error of 0.52 and $\mathrm{SD}=+/-1.65$ for the linear mandibular depth compared to the curvilinear mandibular depth. The mandibular curvilinear arc extended from left tragus to subnasale to right tragus (t-sn-t) and did not have an equivalent linear counterpart 75 . The use of curvilinear measures is gaining application in tooth morphology studies where curvilinear measurements are deemed superior to the conventional linear ones 85,86 .

3D imaging was used for the superficial soft tissue measurements and transverse indices (Figs.9-11). Once again the findings were similar to past work. Currently, the imaging is still a single capture in time and presents limited insight into the true functional assessment. Even though there are several existing packages available for 3D imaging it has yet to become a routine diagnostic tool. There are several reasons for not having 3D imaging in mainstream clinical set ups. Primarily the cost, followed by not completely realistic imaging which still needs refinement for accurate and life-like reproduction of the face. Also, the data acquired from such analyses needs to be unique and provide information that cannot be generated by other more conventional means. Finally, the product needs to be userfriendly and easy to apply by the clinician or auxiliary staff. Above all, the suggestion that $3 \mathrm{D}$ imaging could be a surrogate for lateral cephalograms with predictive correlations obviating the need for serial radiography and radiation exposure, could make it an attractive choice. 


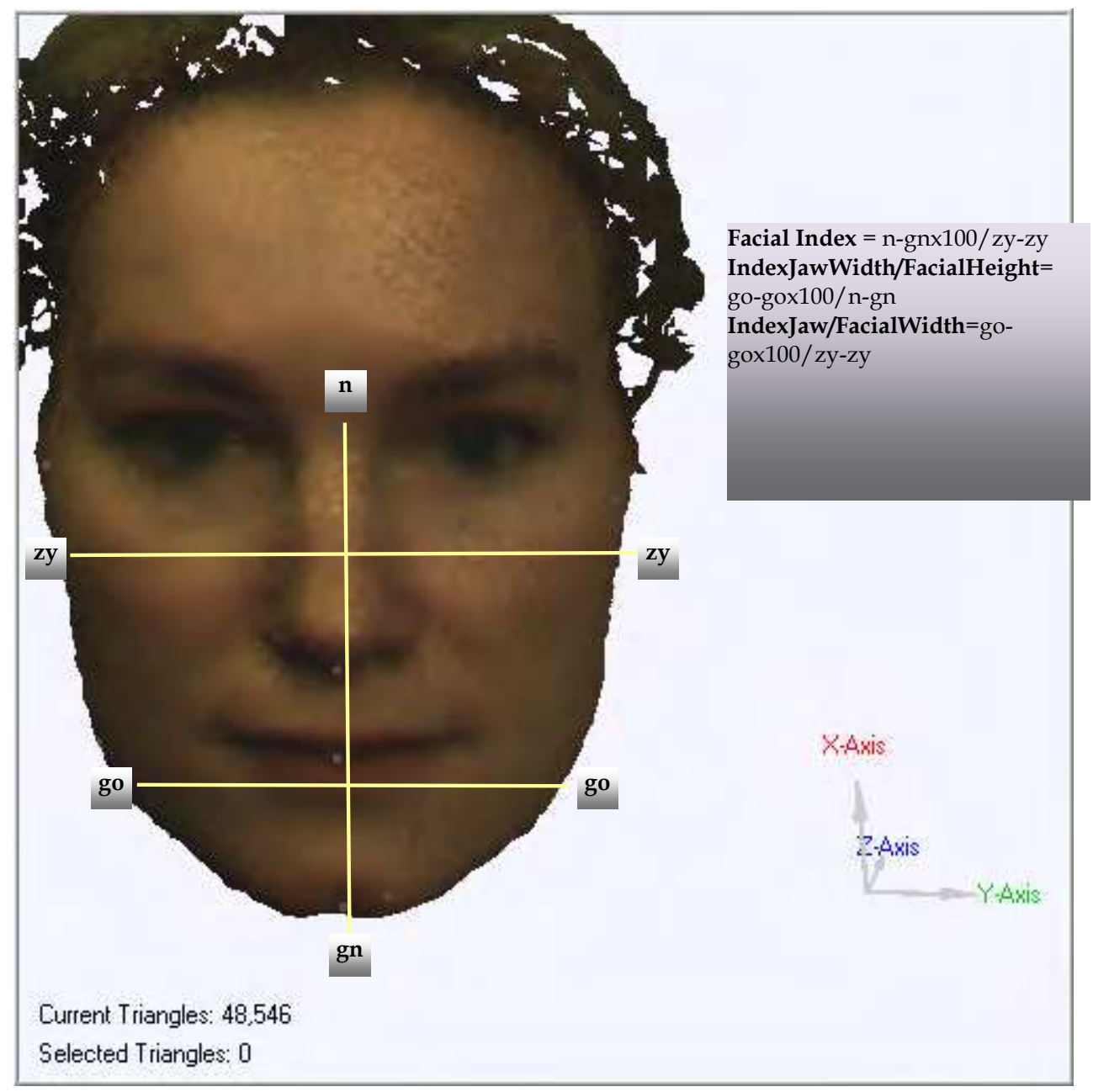

Fig. 9. Anthropometric Indices of Farkas ${ }^{55}$ applied to 3D images for transverse and vertical assessments. 


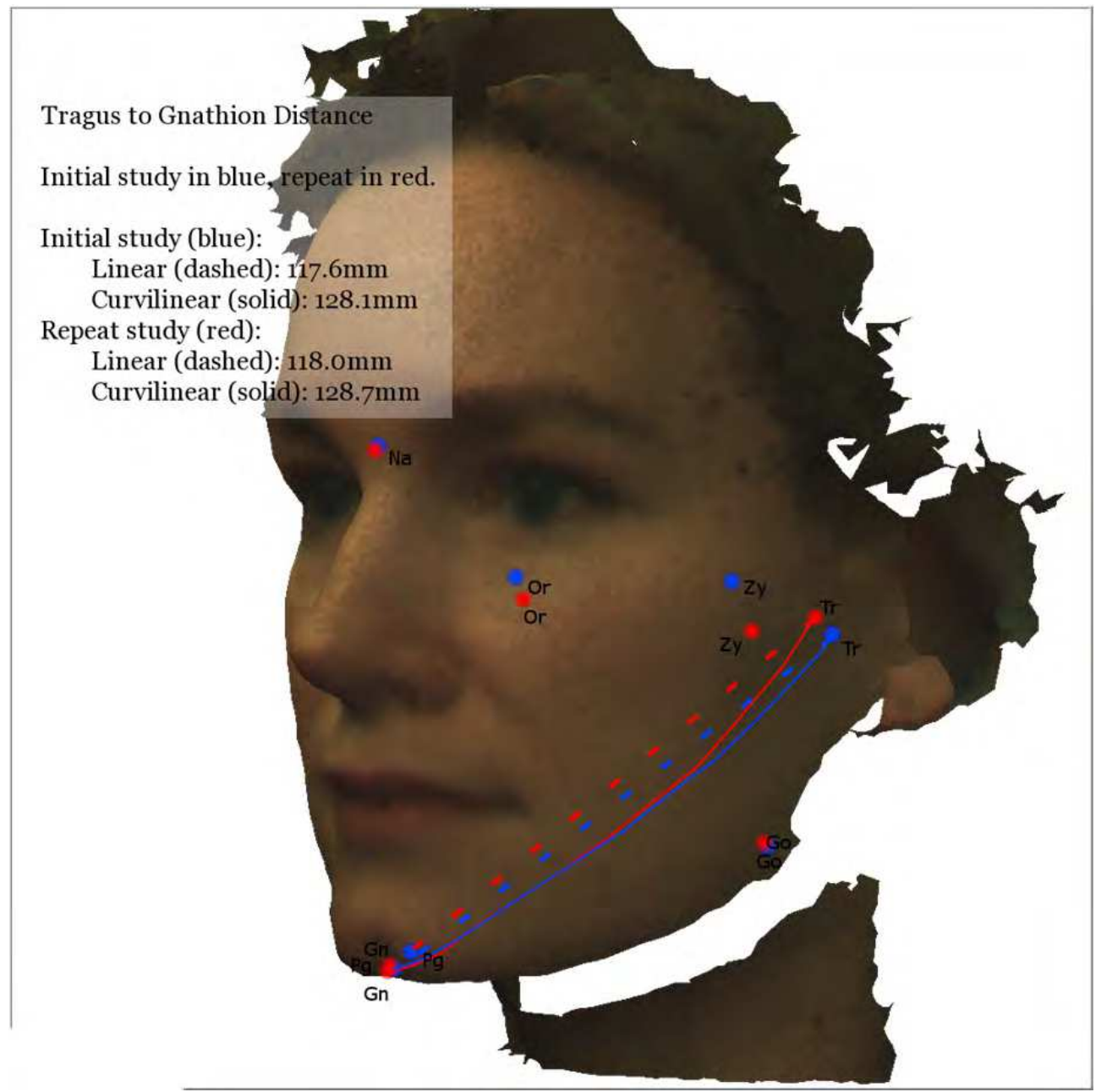

Fig. 10. Curvilinear and linear mandibular measurements for the left side of the subject. There is a clear advantage with 3D images over photographs. 


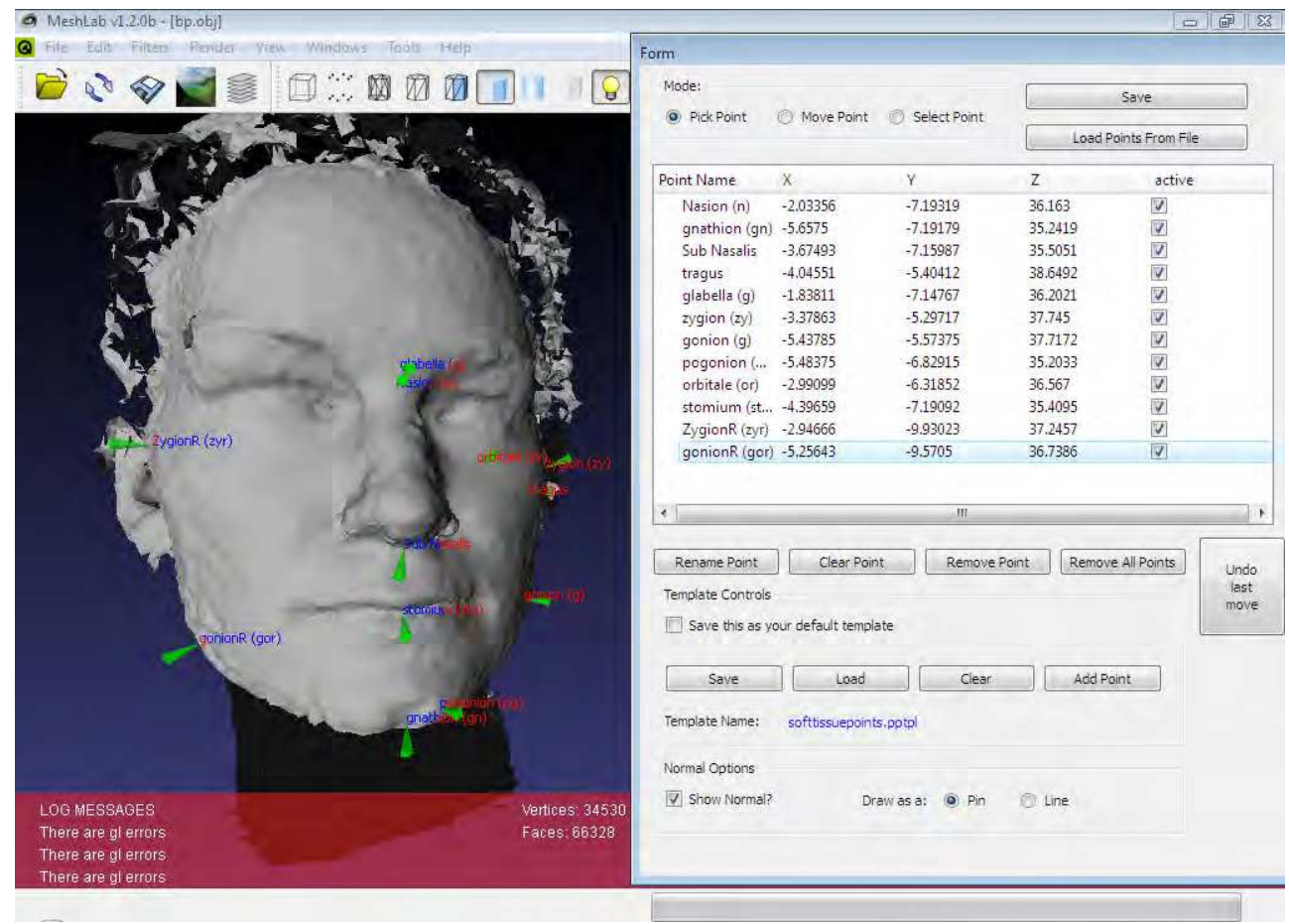

Fig. 11. Analysis of 3D scanned images using MeshLab ${ }^{\circledR}$ shows point selection for computing distances between the landmarks.

Author's study has found high correlation of certain lateral cephalometric variables, particularly the vertical ones, with $3 \mathrm{D}$ imaging indices. However, before it enters into mainstream clinical practice, the following criteria need to be fulfilled.

a. Reliability is considered a composite of repeatability and reproducibility 87 and different 3D imaging techniques have been scrutinized for accuracy and reliability. Kusnoto and Evans 88 used a surface laser scanner (Minolta Vivid 700) to assess various objects ranging from cylinders to cast analyses and facial models. They found accuracy in the range of $1.9+/-0.8 \mathrm{~mm}$ for facial imaging which was not as high as for cast analyses 0.2 $+/-0.2 \mathrm{~mm}$. Hence, one can conclude that the larger the surface to scan and the greater the data acquisition, the higher the error rate with current 3D scans. Likewise, the suggestions for improvement and exploring more user-friendly options in 3D technology have been highlighted in a review article addressing these issues ${ }^{89}$.

b. Standardization is equally essential for the translation of the predictive equations across the board with different imaging packages. This has been norm with many software cephalometric packages currently in use and could become an overall package. 
c. Cost Effectiveness and ease of accessibility with perhaps even free downloads such as used in this study can enhance its wider applicability. Such off-line computer analyses can provide flexibility and effective access ${ }^{90}$. However, one has to be wary of the quality of such softwares; reproducibility, reliability, accuracy of reproduction and ease of manipulation. Perhaps custom-made software packages specifically tailored to orthodontic case assessment 85,86 with higher resolution and reproducibility would be welcomed by the profession. Overall such endeavour will aid in patient education and serve as a vital teaching tool to students to appreciate subtle changes during treatment and growth.

d. Safety Efforts are being made to assess mandibular growth with 3D MRI 91. However, there is real concern about the justification of such expensive investigations and is often under fire for overuse in certain countries. Clearly, for the conventional orthodontic patient such scans would not be routinely recommended.

Multiple investigations used in the past such as CT, MRI and radiographs can be replaced with carefully selected diagnostic and evaluating tools which provide maximum information with minimal hazard along with the added bonus of being cost-effective. The current work has addressed this issue and future investigations should be geared to validate it.

Recent work has explored the correlations between anthropometric and cephalometric measurements of vertical profile ${ }^{92}$. The study found nasion and menton to be highly correlated between the two investigation, but landmarks such as subnasale, supradentale and infradentale varied significantly. This could be due to the overlying soft tissue and its variability among individuals. For this particular reason we chose landmarks that would be more closely related to the cephalometric counterparts such as glabella, nasion, gnathion, subnasale, gonion, zygonion, orbitale, tragus and stomion.

However, due to difficulties in lateral projections inherent to the Structured Light (SL) technique we consistently had difficulty in locating the tragus. Overall, our best and most highly repeatable landmarks were soft tissue subnasale (y-axis) with Dahlberg's statistic $(D S)=0.009$, followed by zygonion (y-axis) DS=0.004, glabella (z-axis) with $D S=0.005$ and stomion (z-axis) $\mathrm{DS}=0.01$. The above mentioned landmarks provide a reliable array of reference points to include in future 3D assessments. However, the majority of the 3D landmarks were within an acceptable range. Perhaps the repeatability could be enhanced with refined software with greater matrix size and pixel ratio ${ }^{87}$. This would further refine the accuracy of the prediction equations and improve overall reliability.

Currently, work is in progress in Liverpool where Brook et al. are evaluating 3D imaging for better assessment of surface contours of teeth $85,86,93$. Precision and accuracy with e-tools will improve the way we measure. Thus, more studies will be needed to explore landmark assessment and measurement.

\section{Prediction equations}

Predictive equations were developed from multiple linear regressions which were significant 18,75 . Unfortunately very few variables qualified as the projection from one medium of investigation to the other was diverse, highlighting that each has its own individual data set that is novel and there is very little overlap. However, those that showed somewhat strong correlations were developed with $B$ - weights which act as constants for a given equation. 


$\begin{array}{lcc}\text { Predictive Equation } & \mathbf{R}^{2} & \text { MSE } \\ \text { Linear Variables } & & \\ \text { R3-R4 }=25.44932+0.48688^{*} \text { t-go } & 0.33 & 5.46 \\ \text { Masseter }=-37.9501+0.81574^{*} \text { FaceHt } & 0.88 & 2.19 \\ \text { N-Gn }=75.76050+0.20701^{*} \text { go-gn }+0.10290^{*} \text { ManDepthLinear } & 0.42 & 3.83 \\ \text { Masseter }=-45.1784+0.67128^{*} \text { FaceHt }+0.20006^{*} \text { Mandiblewidth } & 0.92 & 1.98 \\ \text { Go-Me }=58.13533+0.06039^{*} \text { Mandibulararc } & 0.17 & 4.06 \\ \text { Co-Go }=28.11536+0.76730^{*} \text { t-go } & 0.58 & 5.14 \\ \text { Ar-Go }=-8.69762+2.50677^{*} \text { ManDepthLinear }+- & 0.67 & 4.16 \\ \text { 1.93239*ManDepthCurvilinear } & & \\ & & \\ \text { Angular Variables } & 0.49 & 4.13 \\ \text { GoangleU }=71.06816+-0.36734^{*} \text { ManIncli } & 0.47 & 5.33 \\ \text { Goangle }=144.2894+-0.46133^{*} \text { ManIncli } & & \\ & & \\ \text { Proportional Variables } & 0.01 & 3.06 \\ \text { AFH }=52.67724+0.11825^{*} \text { Indexjawwidthfacialheight } & 0.07 & 2.96 \\ \text { AFH }=52.71398+0.18845^{*} \text { JawIndex } & 0.07 & 3.17 \\ \text { AFH }=54.06144+-0.03102^{*} \text { Indexjawwidthfacialheight }+ & \\ \text { 0.19646*JawIndex } & 0.11 & 6.62 \\ \text { JarabakR }=109.0283+-0.20828^{*} \text { Indexjawfacialwidth } & 0.13 & 6.52 \\ \text { JarabakR }=69.87241+0.24662^{*} \text { IndexJaw-FH } & 0.32 & 6.2 \\ \text { JarabakR }=101.1132+-0.27080^{*} \text { Indexjawfacialwidth }+ & & \\ 0.30918^{*} \text { IndexJaw-FH } & & \end{array}$

Table 2. Predictive Tables for the various 3D imaging variables that can provide information pertaining to lateral cephalometric variables. Starred equations show significance at the level of $\mathrm{p}<0.05$. Linear measurements have the statistically significant predictive equations. Gray bars are the $\beta$-weights.

We used simple methods to produce prediction equations rather than the more resource intensive Besaynian or Monte Carlo factor models with the aim of, decreasing the complexity and making it more clinically applicable. The concept of generating predictive equations from 3D images for lateral cephalometric variable estimation has been presented for the first time. Although, it can be debated that with a small sample size the value of such prediction is questionable, it does set the scene for future work ${ }^{75}$.

Compared to the reported Eigenvalues from Benington et al 94 our values were lower. Also their study was the first to document the masseter volume measurements with high technology 3D US scanning. Likewise, the current study by author did measure masseter volume, albeit indirectly, utilizing a simple, portable US unit that could find application in clinical settings ${ }^{75}$. Similarly, when compared with Radsheer 95 , our values were slightly lower but their study included, 121 adults and previous work with 329 subjects aged 7-22 from a Greek population ${ }^{56}$. Our result differences could be attributed to the sample size and also the population from which they are selected.

The method error indicated that there were certain landmarks that had reduced repeatability. This may be explained by background noise and lack of clear definition in some scans. Palpation is generally advantageous in precise positioning of soft tissue gonion, but it is considered a difficult point overall to determine even in anthropology ${ }^{55}$. Nasion (n) 
and subnasale (sn) were relatively easily identified on the 3D images. For a better view, the image was rotated upwards by $30^{\circ}$. This is an advantage of the scans because repositioning the live patient can be difficult and sometimes embarrassing. The accuracy and repeatability of 3D Imaging has been documented as exceptional 96 and, as with most recordings, in order to eliminate inter-operator variability all measurements should be made by the same investigator. The angular measurements are dependent on head position and need to be standardized across the sample 55 .

Baumrind eloquently stated that the "craniofacial complex system needs to be evaluated from different perspectives as no single view would do justice in its evaluation and future treatment planning" 97. 3D imaging has extended not only to facial surface analyses but is extending to cephalometry as well ${ }^{98}$. Subtle soft tissue changes have been studied extensively in recent work particularly with pre- and post-treatment outcomes 8,64,80,89,91,99,100 . Similar interest with mandibular growth changes ${ }^{91}$ and four-dimensional analyses for the TMD 100 are gaining momentum in diagnostic imaging. A common critique with new imaging techniques has been the reliability which is of concern and can be addressed with the development of self -calibrating measuring systems 64 .

New directions in technology will soon be evident with the need to enhance the quality of 3D images with more real-life effect. This would assist in patient education and teaching sessions for dental students. Moreover, programs with substantial mouse manipulation create undue hand and wrist fatigue whereas touch screen options would be ergonomically valuable.

Clinical applications of 3D imaging are vast and numerous. From treatment planning to preand post-treatment evaluation, the images can be manipulated from any direction providing in-depth analysis of the case without patient recalls and inconvenience of anthropometry. It is becoming a vital tool in orthognathic surgery planning, patient education, "teleorthodontics" 7 to manage global movement of patients, and where interdisciplinary treatments are sought. It is an effective recording method for various facial asymmetries 96 and severe craniofacial dysostoses, hemifacial microsomias 101, and where simple photographs have serious limitations. The non-invasive nature of 3-D imaging will make its application widely accepted for sequential evaluation in growing children and on controls for research 96.

However, the idea of obviating lateral cephalograms entirely may not yet be the case because radiographs still provide valuable skeletal and dental information vital for initial treatment planning. Moreover, we do acknowledge the limitations of prediction because as with any prognostic approach, particularly in a biological system, there will be variations. However, a method that can assist the clinician in reducing the number of radiographic investigations would surely be welcomed by the public and profession alike.

\section{Other investigations}

a. Genetic profiling

Research is ever expanding in this novel frontier and will offer the possibility of diagnosis in Orthodontics. It already is promising in screening individuals with high risk of root resorption ${ }^{102}$.

Predictive and presymptomatic testing is already creating a lot of media interest and long term implications with financial issues related to health insurance. Most importantly the possibility of genetic discrimination may occur. 
Recent work from Hong Kong is uncovering the genetic etiology of Class III malocclusion ${ }^{103,104 .}$

The genetic profiling is evolving and has to be refined to be reliable.

Incomplete penetrance of the genetic code may prove challenging when considering probable malocclusion in the offspring. However, some conditions that have had high genetic predisposition e.g Class III skeletal patterns and anterior open bites (AOB) could provide useful genetic information with the probability of expression.

However, caution has to be exercised as malocclusion is multifactorial and with global migrations miscegenation is increasing with leading to genetic dilution so to speak.

b. Heat sensitive Scans

Moss has shown heat sensitive scans can be utilized to determine the "hot spots" of growth particularly following Orthodontic intervention ${ }^{79}$. This is a simple non-invasive investigation albeit costly.

c. Image Fusion

The latest of combining various investigations for a holistic evaluation process has been aptly described as "Image fusion" 105 assisting in facial triad analysis ( namely soft tissues, skeletal basis and dentition). The aim of this amalgamation is to recreate a virtual head for treatment planning, long term follow up and documentation. Moreover, it may provide a realistic prediction model in the future.

d. MRI

MRI ( Magnetic Resonance Imaging) although radiation free is a costly investigation, with implication for time and quality of life ( unbearably loud at the moment). MRI usage is limited in Orthodontics needs to be justified and avoided when possible.

Previous work ${ }^{3}$ has affirmed that lower face height and masseter muscle thickness have inverse correlation. Generally, the increased lower face height individuals will present with classic cephalometric characteristics such as large gonial angles, steep mandibular planes and reduced posterior face height. The masseter muscle cross-section has been measured with MRI's and found to be significantly smaller by nearly $30 \%$ in the dolichofacial types ${ }^{3}$.

A recent study has compared volume of masseter muscle derived from MRI with vertical facial dimensions and found volume to be more relevant than cross-sectional area 106. Moreover, the posterior face height was significantly correlated to masseter muscle volume. Although, MRI has shown high resolution for TMJ scans ${ }^{107}$ it needs to refine to a small field of view 108 for acceptance as an investigation tool.

e. Videofluoroscopy

Even though not entirely radiation free Videofluoroscopy is showing promising results in the investigation of Obstructive Sleep Apnoea (OSA) ${ }^{109}$. There is the issue for 2D instead of $3 \mathrm{D}$ as found in CBVT scans, perhaps image fusion would add to its limitations.

f. Videos

Increasingly videos are being recorded to provide a real time assessment on Orthodontic patient smiles, speech and expressions which were not possible with static shots in repose and unnatural smiles. Many of the softwares for diagnosis and data storage are adding video as an important tab to achieve patient motions.

\section{Conclusion}

Even though the findings from this study are not clinically applicable it has highlighted the importance of finding cost effective and non-invasive methods of investigations for 
Orthodontic case assessment. There is now a fast moving trend towards 3D imaging and indeed the lateral cephalometric may phase out in years ahead.

In orthodontics there is a strong association between form and function 110 . This has been studied extensively and proved with strong correlation that exists between the soft tissue and underlying osseous foundation. However, there are not many studies from the soft tissue perspective, particularly, the muscles of mastication including the masseter.

There is definitely scope for US for assessment of masseter muscle in real-time. This has been documented widely in the literature with masseter muscle thickness demonstrating differences in posterior crossbite cases and their relationship to TMDs 5,54,111,112. But there is concern that some findings can be controversial and others produce non-conclusive results. For example, some studies 113 found the crossbite side had thinner masseter muscle. Obviously, 3D US is superior in function and would be better for oro-facial applications 94 provided it is cost-effective. One can also anticipate the rapid advancement in technology and 4D US may well be the future for diagnosis and treatment evaluation.

Our understanding of malocclusion has come a long way but it is multidimensional, multifaceted and highly variable and needs to be analyzed from several different perspectives. The emphasis is shifting from static, radiation-based investigations which are a snap shot in time to dynamic real-time recordings of soft tissue function. The fourth dimension in combination with conventional diagnostic tools could provide a comprehensive single diagnostic package that would not only assist in complete records diagnosis and evaluation but provide predictions for future expected changes.

\section{References}

[1] Gibson C: 3D video software the next big thing?, The Adeladian Adelaide, 2009

[2] Raadsheer MC, Van Eijden TM, Van Spronsen PH, et al: A comparison of human masseter muscle thickness measured by ultrasonography and magnetic resonance imaging. Arch Oral Biol 39:1079-84, 1994

[3] van Spronsen PH, Weijs WA, Valk J, et al: A comparison of jaw muscle cross-sections of long-face and normal adults. J Dent Res 71:1279-85, 1992

[4] Hussain AM, Packota G, Major PW, et al: Role of different imaging modalities in assessment of temporomandibular joint erosions and osteophytes: a systematic review. Dentomaxillofac Radiol 37:63-71, 2008

[5] Jank S, Rudisch A, Bodner G, et al: High-resolution ultrasonography of the TMJ: helpful diagnostic approach for patients with TMJ disorders ? J Craniomaxillofac Surg 29:366-71, 2001

[6] Weijs WA, Hillen B: Correlations between the cross-sectional area of the jaw muscles and craniofacial size and shape. Am J Phys Anthropol 70:423-31, 1986

[7] Hajeer MY, Millett DT, Ayoub AF, et al: Applications of 3D imaging in orthodontics: part II. J Orthod 31:154-62, 2004

[8] Kau CH, Richmond S: Three-dimensional analysis of facial morphology surface changes in untreated children from 12 to 14 years of age. Am J Orthod Dentofacial Orthop 134:751-60, 2008

[9] Kau CH, Richmond S, Incrapera A, et al: Three-dimensional surface acquisition systems for the study of facial morphology and their application to maxillofacial surgery. Int J Med Robot 3:97-110, 2007 
[10] Broadbent BH: A new $\mathrm{x}$ ray technique and its application to orthodontics. Angle Orthod:45-66, 1931

[11] Bjork A, Skieller V: Contrasting mandibular growth and facial development in long face syndrome, juvenile rheumatoid polyarthritis, and mandibulofacial dysostosis. J Craniofac Genet Dev Biol Suppl 1:127-38, 1985

[12] Skieller V, Bjork A, Linde-Hansen T: Prediction of mandibular growth rotation evaluated from a longitudinal implant sample. Am J Orthod 86:359-70, 1984

[13] Vig PS, Spalding PM, Lints RR: Sensitivity and specificity of diagnostic tests for impaired nasal respiration. Am J Orthod Dentofacial Orthop 99:354-60, 1991

[14] Trpkova B, Major P, Prasad N, et al: Cephalometric landmarks identification and reproducibility: a meta analysis. Am J Orthod Dentofacial Orthop 112:165-70, 1997

[15] Mankovich NJ, Samson D, Pratt W, et al: Surgical planning using three-dimensional imaging and computer modeling. Otolaryngol Clin North Am 27:875-89, 1994

[16] Rueda S, Alcaniz M: An approach for the automatic cephalometric landmark detection using mathematical morphology and active appearance models. Med Image Comput Comput Assist Interv Int Conf Med Image Comput Comput Assist Interv 9:159-66, 2006

[17] Naser-Ud-Din S, Sowman PF, Sampson WJ, et al: Masseter length determines muscle spindle reflex excitability during jaw-closing movements. Am J Orthod Dentofacial Orthop 139:e305-13, 2011

[18] Naser-Ud-Din S: Analysis \& Correlation Study of Human Masseter Muscle with EMG, US \& 3D Imaging Orthodontics. Adelaide, University of Adelaide, 2009, pp 214

[19] Hultborn H: State-dependent modulation of sensory feedback. J Physiol 533:5-13, 2001

[20] Moller E: The chewing apparatus. An electromyographic study of the action of the muscles of mastication and its correlation to facial morphology. Acta Physiol Scand Suppl 280:1-229, 1966

[21] Perry HT, Harris SC: Role of the neuromuscular system in functional activity of the mandible. J Am Dent Assoc 48:665-73, 1954

[22] Ahlgren J: An intercutaneous needle electrode for kinesiologic EMG studies. Acta Odontol Scand 25:15-9, 1967

[23] Huck NL, Abbink JH, Hoogenkamp E, et al: Exteroceptive reflexes in jaw-closing muscle EMG during rhythmic jaw closing and clenching in man. Exp Brain Res 162:230-8, 2005

[24] van der Glas HW, van der Bilt A, Abbink JH, et al: Functional roles of oral reflexes in chewing and biting: phase-, task- and site-dependent reflex sensitivity. Arch Oral Biol 52:365-9, 2007

[25] Goldberg LJ: Masseter muscle excitation induced by stimulation of periodontal and gingival receptors in man. Brain Res 32:369-81, 1971

[26] Fogle LL, Glaros AG: Contributions of facial morphology, age, and gender to EMG activity under biting and resting conditions: a canonical correlation analysis. J Dent Res 74:1496-500, 1995

[27] Ringqvist M: Isometric bite force and its relation to dimensions of the facial skeleton. Acta Odontol Scand 31:35-42, 1973

[28] Ingervall B, Thilander B: Relation between facial morphology and activity of the masticatory muscles. J Oral Rehabil 1:131-47, 1974 
[29] Ueda HM, Miyamoto K, Saifuddin M, et al: Masticatory muscle activity in children and adults with different facial types. Am J Orthod Dentofacial Orthop 118:63-8, 2000

[30] Garcia-Morales P, Buschang PH, Throckmorton GS, et al: Maximum bite force, muscle efficiency and mechanical advantage in children with vertical growth patterns. Eur J Orthod 25:265-72, 2003

[31] Morimitsu T, Nokubi T, Nagashima T, et al: [Relationship between orofaciocranial morphologic factors and electromyographic activities of the masticatory muscles]. Nihon Ago Kansetsu Gakkai Zasshi 1:162-71, 1989

[32] Turker KS: Electromyography: some methodological problems and issues. Phys Ther 73:698-710, 1993

[33] Tuxen A, Bakke M, Pinholt EM: Comparative data from young men and women on masseter muscle fibres, function and facial morphology. Arch Oral Biol 44:509-18, 1999

[34] Naser-Ud-Din S, Sowman PF, Dang H, et al: Modulation of masseteric reflexes by simulated mastication. J Dent Res 89:61-5, 2010

[35] Yoshimi H, Sasaguri K, Tamaki K, et al: Identification of the occurrence and pattern of masseter muscle activities during sleep using EMG and accelerometer systems. Head Face Med 5:7, 2009

[36] Turker KS: Reflex control of human jaw muscles. Crit Rev Oral Biol Med 13:85-104, 2002

[37] Kubota K, Masegi T: Muscle spindle supply to the human jaw muscle. J Dent Res 56:901-9, 1977

[38] Yemm R: The orderly recruitment of motor units of the masseter and temporal muscles during voluntary isometric contraction in man. J Physiol 265:163-74, 1977

[39] Eriksson PO, Thornell LE: Relation to extrafusal fibre-type composition in musclespindle structure and location in the human masseter muscle. Arch Oral Biol 32:483-91, 1987

[40] Rowlerson A, Mascarello F, Barker D, et al: Muscle-spindle distribution in relation to the fibre-type composition of masseter in mammals. J Anat 161:37-60, 1988

[41] Morimoto T, Inoue T, Masuda $Y$, et al: Sensory components facilitating jaw-closing muscle activities in the rabbit. Exp Brain Res 76:424-40, 1989

[42] Thexton AJ: Mastication and swallowing: an overview. Br Dent J 173:197-206, 1992

[43] Soboleva U, Laurina L, Slaidina A: The masticatory system--an overview. Stomatologija 7:77-80, 2005

[44] Ueda HM, Ishizuka Y, Miyamoto K, et al: Relationship between masticatory muscle activity and vertical craniofacial morphology. Angle Orthod 68:233-8, 1998

[45] Brinkworth RS, Turker KS: A method for quantifying reflex responses from intramuscular and surface electromyogram. J Neurosci Methods 122:179-93, 2003

[46] Bakke M, Tuxen A, Vilmann P, et al: Ultrasound image of human masseter muscle related to bite force, electromyography, facial morphology, and occlusal factors. Scand J Dent Res 100:164-71, 1992

[47] Bertram S, Rudisch A, Bodner G, et al: The short-term effect of stabilization-type splints on the local asymmetry of masseter muscle sites. J Oral Rehabil 28:1139-43, 2001

[48] Close PJ, Stokes MJ, L'Estrange PR, et al: Ultrasonography of masseter muscle size in normal young adults. J Oral Rehabil 22:129-34, 1995

[49] Kubo K, Kawata T, Ogawa T, et al: Outer shape changes of human masseter with contraction by ultrasound morphometry. Arch Oral Biol 51:146-53, 2006 
[50] Serra MD, Duarte Gaviao MB, dos Santos Uchoa MN: The use of ultrasound in the investigation of the muscles of mastication. Ultrasound Med Biol 34:1875-84, 2008

[51] Naser-Ud-Din S, Sampson WJ, Dreyer CW, et al: Ultrasound measurements of the masseter muscle as predictors of cephalometric indices in orthodontics: a pilot study. Ultrasound Med Biol 36:1412-21, 2010

[52] Prabhu NT, Munshi AK: Measurement of masseter and temporalis muscle thickness using ultrasonographic technique. J Clin Pediatr Dent 19:41-4, 1994

[53] Kiliaridis S, Katsaros C, Karlsson S: Effect of masticatory muscle fatigue on craniovertical head posture and rest position of the mandible. Eur J Oral Sci 103:127-32, 1995

[54] Pereira LJ, Gaviao MB, Bonjardim LR, et al: Ultrasound and tomographic evaluation of temporomandibular joints in adolescents with and without signs and symptoms of temporomandibular disorders: a pilot study. Dentomaxillofac Radiol 36:402-8, 2007

[55] Farkas L: Anthropometry of the Head and Face (ed second edition). New York Raven Press Ltd, 1994 pp. 405

[56] Raadsheer MC, Kiliaridis S, Van Eijden TM, et al: Masseter muscle thickness in growing individuals and its relation to facial morphology. Arch Oral Biol 41:323-32, 1996

[57] Kiliaridis S, Kalebo P: Masseter muscle thickness measured by ultrasonography and its relation to facial morphology. J Dent Res 70:1262-5, 1991

[58] Hatch JP, Shinkai RS, Sakai S, et al: Determinants of masticatory performance in dentate adults. Arch Oral Biol 46:641-8, 2001

[59] Emshoff R, Bertram S, Brandlmaier I, et al: Ultrasonographic assessment of local crosssectional dimensions of masseter muscle sites: a reproducible technique? J Oral Rehabil 29:1059-62, 2002

[60] Satiroglu F, Arun T, Isik F: Comparative data on facial morphology and muscle thickness using ultrasonography. Eur J Orthod 27:562-7, 2005

[61] Burke PH, Beard FH: Stereophotogrammetry of the face. A preliminary investigation into the accuracy of a simplified system evolved for contour mapping by photography. Am J Orthod 53:769-82, 1967

[62] Da Silveira AC, Daw JL, Jr., Kusnoto B, et al: Craniofacial applications of threedimensional laser surface scanning. J Craniofac Surg 14:449-56, 2003

[63] Ireland AJ, McNamara C, Clover MJ, et al: 3D surface imaging in dentistry - what we are looking at. Br Dent J 205:387-92, 2008

[64] Kopp S, Kuhmstedt P, Notni G, et al: G-scan--mobile multiview 3-D measuring system for the analysis of the face. Int J Comput Dent 6:321-31, 2003

[65] Mah J: 3D imaging in private practice. Am J Orthod Dentofacial Orthop 121:14A, 2002

[66] Sachdeva RC: SureSmile technology in a patient--centered orthodontic practice. J Clin Orthod 35:245-53, 2001

[67] Arridge S, Moss JP, Linney AD, et al: Three dimensional digitization of the face and skull. J Maxillofac Surg 13:136-43, 1985

[68] Moss JP, Linney AD, Grindrod SR, et al: Three-dimensional visualization of the face and skull using computerized tomography and laser scanning techniques. Eur J Orthod 9:247-53, 1987

[69] Aung M, Sobel DF, Gallen CC, et al: Potential contribution of bilateral magnetic source imaging to the evaluation of epilepsy surgery candidates. Neurosurgery 37:1113-20; discussion 1120-1, 1995 
[70] Moss JP: The use of three-dimensional imaging in orthodontics. Eur J Orthod 28:416-25, 2006

[71] Quintero JC, Trosien A, Hatcher D, et al: Craniofacial imaging in orthodontics: historical perspective, current status, and future developments. Angle Orthod 69:491-506, 1999

[72] Lee JY, Han Q, Trotman CA: Three-dimensional facial imaging: accuracy and considerations for clinical applications in orthodontics. Angle Orthod 74:587-93, 2004

[73] Nguyen CX, Nissanov J, Ozturk C, et al: Three-dimensional imaging of the craniofacial complex. Clin Orthod Res 3:46-50, 2000

[74] Vallance S: (personal communications) Structured Light technique with Mona Lisa Imaging System. Adelaide, 2009

[75] Naser-ud-Din S, Thoirs K, Sampson WJ: Ultrasonography, lateral cephalometry and 3D imaging of the human masseter muscle. Orthod Craniofac Res 14:33-43, 2011

[76] Nute SJ, Moss JP: Three-dimensional facial growth studied by optical surface scanning. J Orthod 27:31-8, 2000

[77] Darwis WE, Messer LB, Thomas CD: Assessing growth and development of the facial profile. Pediatr Dent 25:103-8, 2003

[78] Bourne CO, Kerr WJ, Ayoub AF: Development of a three-dimensional imaging system for analysis of facial change. Clin Orthod Res 4:105-111, 2001

[79] Clark W: Twin Block Functional Therapy Applications in Dentofacial Orthopaedics (ed Second). London, Mosby, 2002

[80] Sharma AA, Lee RT: Prospective clinical trial comparing the effects of conventional Twin-block and mini-block appliances: Part 2. Soft tissue changes. Am J Orthod Dentofacial Orthop 127:473-82, 2005

[81] Ismail SF, Moss JP, Hennessy R: Three-dimensional assessment of the effects of extraction and nonextraction orthodontic treatment on the face. Am J Orthod Dentofacial Orthop 121:244-56, 2002

[82] Ayoub AF, Xiao Y, Khambay B, et al: Towards building a photo-realistic virtual human face for craniomaxillofacial diagnosis and treatment planning. Int J Oral Maxillofac Surg 36:423-8, 2007

[83] Baik HS, Lee HJ, Lee KJ: A proposal for soft tissue landmarks for craniofacial analysis using 3-dimensional laser scan imaging. World J Orthod 7:7-14, 2006

[84] Nechala P, Mahoney J, Farkas LG: Maxillozygional anthropometric landmark: a new morphometric orientation point in the upper face. Ann Plast Surg 41:402-9, 1998

[85] Smith R, Zaitoun H, Coxon T, et al: Defining new dental phenotypes using 3-D image analysis to enhance discrimination and insights into biological processes. Arch Oral Biol, 2008

[86] Brook AH, Pitts NB, Yau F, et al: An image analysis system for the determination of tooth dimensions from study casts: comparison with manual measurements of mesio-distal diameter. J Dent Res 65:428-31, 1986

[87] Kneafsey LC, Cunningham SJ, Petrie A, et al: Prediction of soft-tissue changes after mandibular advancement surgery with an equation developed with multivariable regression. Am J Orthod Dentofacial Orthop 134:657-64, 2008

[88] Kusnoto B, Evans CA: Reliability of a 3D surface laser scanner for orthodontic applications. Am J Orthod Dentofacial Orthop 122:342-8, 2002 
[89] Papadopoulos MA, Christou PK, Athanasiou AE, et al: Three-dimensional craniofacial reconstruction imaging. Oral Surg Oral Med Oral Pathol Oral Radiol Endod 93:38293, 2002

[90] Fuhrmann RA, Schnappauf A, Diedrich PR: Three-dimensional imaging of craniomaxillofacial structures with a standard personal computer. Dentomaxillofac Radiol 24:260-3, 1995

[91] Cevidanes LH, Franco AA, Gerig G, et al: Assessment of mandibular growth and response to orthopedic treatment with 3-dimensional magnetic resonance images. Am J Orthod Dentofacial Orthop 128:16-26, 2005

[92] Budai M, Farkas LG, Tompson B, et al: Relation between anthropometric and cephalometric measurements and proportions of the face of healthy young white adult men and women. J Craniofac Surg 14:154-61; discussion 162-3, 2003

[93] Khalaf K, Robinson DL, Elcock C, et al: Tooth size in patients with supernumerary teeth and a control group measured by image analysis system. Arch Oral Biol 50:243-8, 2005

[94] Benington PC, Gardener JE, Hunt NP: Masseter muscle volume measured using ultrasonography and its relationship with facial morphology. Eur J Orthod 21:65970, 1999

[95] Raadsheer MC, van Eijden TM, van Ginkel FC, et al: Contribution of jaw muscle size and craniofacial morphology to human bite force magnitude. J Dent Res 78:31-42, 1999

[96] Hartmann J, Meyer-Marcotty P, Benz M, et al: Reliability of a Method for Computing Facial Symmetry Plane and Degree of Asymmetry Based on 3D-data. J Orofac Orthop 68:477-90, 2007

[97] Baumrind S: Taking stock: a critical perspective on contemporary orthodontics. Orthod Craniofac Res 7:150-6, 2004

[98] Togashi K, Kitaura H, Yonetsu K, et al: Three-dimensional cephalometry using helical computer tomography: measurement error caused by head inclination. Angle Orthod 72:513-20, 2002

[99] Martensson B, Ryden H: The holodent system, a new technique for measurement and storage of dental casts. Am J Orthod Dentofacial Orthop 102:113-9, 1992

[100] Terajima M, Endo M, Aoki Y, et al: Four-dimensional analysis of stomatognathic function. Am J Orthod Dentofacial Orthop 134:276-87, 2008

[101] Takashima M, Kitai N, Murakami S, et al: Volume and shape of masticatory muscles in patients with hemifacial microsomia. Cleft Palate Craniofac J 40:6-12, 2003

[102] Low E, Zoellner H, Kharbanda OP, et al: Expression of mRNA for osteoprotegerin and receptor activator of nuclear factor kappa beta ligand (RANKL) during root resorption induced by the application of heavy orthodontic forces on rat molars. Am J Orthod Dentofacial Orthop 128:497-503, 2005

[103] Xue F, Wong R, Rabie AB: Identification of SNP markers on 1 p36 and association analysis of EPB41 with mandibular prognathism in a Chinese population. Arch Oral Biol 55:867-72, 2010

[104] Xue F, Wong RW, Rabie AB: Genes, genetics, and Class III malocclusion. Orthod Craniofac Res 13:69-74, 2010 
[105] Plooij JM, Maal TJ, Haers P, et al: Digital three-dimensional image fusion processes for planning and evaluating orthodontics and orthognathic surgery. A systematic review. Int J Oral Maxillofac Surg 40:341-52, 2011

[106] Boom HP, van Spronsen PH, van Ginkel FC, et al: A comparison of human jaw muscle cross-sectional area and volume in long- and short-face subjects, using MRI. Arch Oral Biol 53:273-81, 2008

[107] Toll DE, Popovic N, Drinkuth N: The use of MRI diagnostics in orthognathic surgery: prevalence of TMJ pathologies in Angle Class I, II, III patients. J Orofac Orthop 71:68-80, 2010

[108] Antonio GE, Griffith JF, Yeung DK: Small-field-of-view MRI of the knee and ankle. AJR Am J Roentgenol 183:24-8, 2004

[109] Johal A, Sheriteh Z, Battagel J, et al: The use of videofluoroscopy in the assessment of the pharyngeal airway in obstructive sleep apnoea. Eur J Orthod 33:212-9, 2011

[110] Naini FB, Moss JP: Three-dimensional assessment of the relative contribution of genetics and environment to various facial parameters with the twin method. Am J Orthod Dentofacial Orthop 126:655-65, 2004

[111] Emshoff R, Brandlmaier I, Bodner G, et al: Condylar erosion and disc displacement: detection with high-resolution ultrasonography. J Oral Maxillofac Surg 61:877-81, 2003

[112] Landes CA, Sterz M: Evaluation of condylar translation by sonography versus axiography in orthognathic surgery patients. J Oral Maxillofac Surg 61:1410-7, 2003

[113] Kiliaridis S, Mahboubi PH, Raadsheer MC, et al: Ultrasonographic thickness of the masseter muscle in growing individuals with unilateral crossbite. Angle Orthod 77:607-11, 2007 


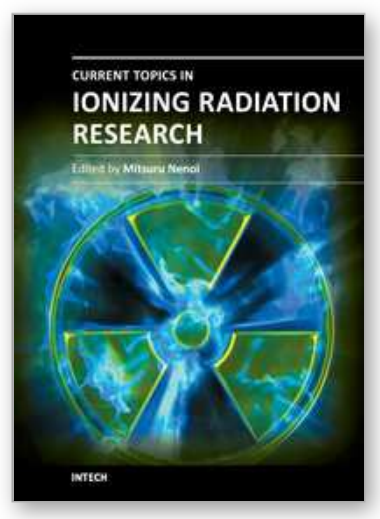

\author{
Current Topics in lonizing Radiation Research \\ Edited by Dr. Mitsuru Nenoi
}

ISBN 978-953-51-0196-3

Hard cover, 840 pages

Publisher InTech

Published online 12, February, 2012

Published in print edition February, 2012

Since the discovery of $X$ rays by Roentgen in 1895 , the ionizing radiation has been extensively utilized in a variety of medical and industrial applications. However people have shortly recognized its harmful aspects through inadvertent uses. Subsequently people experienced nuclear power plant accidents in Chernobyl and Fukushima, which taught us that the risk of ionizing radiation is closely and seriously involved in the modern society. In this circumstance, it becomes increasingly important that more scientists, engineers and students get familiar with ionizing radiation research regardless of the research field they are working. Based on this idea, the book "Current Topics in lonizing Radiation Research" was designed to overview the recent achievements in ionizing radiation research including biological effects, medical uses and principles of radiation measurement.

\title{
How to reference
}

In order to correctly reference this scholarly work, feel free to copy and paste the following:

Shazia Naser-Ud-Din (2012). Alternatives to Radiation Investigations in Orthodontics, Current Topics in Ionizing Radiation Research, Dr. Mitsuru Nenoi (Ed.), ISBN: 978-953-51-0196-3, InTech, Available from: http://www.intechopen.com/books/current-topics-in-ionizing-radiation-research/alternatives-to-radiationinvestigations-in-orthodontics

\section{INTECH}

open science | open minds

\author{
InTech Europe \\ University Campus STeP Ri \\ Slavka Krautzeka 83/A \\ 51000 Rijeka, Croatia \\ Phone: +385 (51) 770447 \\ Fax: +385 (51) 686166 \\ www.intechopen.com
}

\author{
InTech China \\ Unit 405, Office Block, Hotel Equatorial Shanghai \\ No.65, Yan An Road (West), Shanghai, 200040, China \\ 中国上海市延安西路65号上海国际贵都大饭店办公楼 405 单元 \\ Phone: +86-21-62489820 \\ Fax: $+86-21-62489821$
}


(C) 2012 The Author(s). Licensee IntechOpen. This is an open access article distributed under the terms of the Creative Commons Attribution 3.0 License, which permits unrestricted use, distribution, and reproduction in any medium, provided the original work is properly cited. 